\section{RESEARCH IN BASIC MEDICAL SCIENCES: CHALLENGES AND OPPORTUNITIES}

\author{
Zilli Huma $^{\natural}$, Jawad Ahmed ${ }^{2}$
}

THIS ARTICLE MAY BE CITED AS: Huma Z, Ahmed J. Research in basic medical sciences: challenges and opportunities. Khyber Med Univ J 2018; $10(4):|8|-2$.

T he one overarching aim of scientific research conducted in the medical field is to improve the health of the human species. The approach though may vary from pure basic, applied to epidemiological.

Basic research or bench research provides the first stepping stone towards research at the bedside. A stronger and wider foundation would positively influence the strength and stability of applied research that follows. It has been shown that most pre-clinical trials $(80$ $90 \%$ ) do not extend into the clinical trial phase;' thus making basic research a prerequisite of further clinical research. This foundation knowledge comes from traditional disciplines of Anatomy, Physiology, Biochemistry, Pharmacology, Histopathology, Haematology and Microbiology. The $21^{\text {st }}$ Century has seen the continuing development of sciences amalgamated and rearranged according to the techniques used from in-vitro cell cultures, to in-vivo animal studies and even virtual modeling of proteins and enzymes. $^{2}$

Research over the past 50 years with the discovery of the double helix of the DNA and the human genome project has led to the newer and emerging fields like molecular biology and genetics leading to a better understanding of causative mechanisms of illnesses. ${ }^{3}$ This breakthrough research at the cellular, sub-cellular and molecular levels has expanded the frontiers of research further than the mere scope of human senses with the advent of more powerful hyper-resolution microscopes and precision techniques. ${ }^{4}$ How else would there be the fields of personalised medicine or theranostics working through cancer genomics, pharmacogenomics or systems biology; tailored to the individual, based on their predicted response or risk of disease. ${ }^{5}$
Scientists have defined basic science research as aimed towards pursuing fundamental questions of natural systems and organisms. Basic science uses hypothesis driven specifically designed experiments in testing the underlying pathogenesis of diseases which can be modified and revised, again and again leading to conclusive evidence of proof or disproof of the hypothesis. This is in contrast to goal-oriented research i.e. applied or inter-disciplinary that has been acclaimed for its practicality.

\section{Challenges}

One of the most pressing issues in basic sciences research is financial resources. The development and up-gradation of laboratories with state of the art equipment is a huge endeavor for developed countries where a study showed $51 \%$ faculty identifying this as a barrier to research let alone developing ones. ${ }^{6}$ Although without doubt the applicability and visibility of applied or clinical research appears to have a greater and immediate impact, the importance of research in the basic medical or for that matter dental science cannot be denied.

The amount of research work and clocked hours at the bench side that may or may not lead to a significant breakthrough in treatment of diseases is another mitigating factor on conducting fundamental research. A scholar of this field spends years to be able to achieve a small fraction of results whereas the majority of clinical research is conducted as a part time effort with a greater projection. ${ }^{7}$

Culturally funding bodies in our part of the world promulgate the idea of short term impact and applicability directly translated into tangible outputs rather than seemingly obscure ideas that are the mainstay of basic science research. As so
I Department of Anatomy, Institute of Basic Medical Sciences, Khyber Medical University, Peshawar, Pakistan Email凹: surghuma73@gmail.com Contact \# : 92-3209894379

2 Dean Basic Medical Sciences, Khyber Medical University, Peshawar, Pakistan

pertinently questioned by Dyna (2016) "Why would a nation that cannot feed its people try to send a spacecraft to Mars?". The answer would be why not? Many of ours problems can be solved by us by targeting local issues from antibiotic resistance to malnutrition rather than looking towards the developed world to solve these problems.

\section{Opportunities}

The change of perception of basic research as an obscure research needs to be addressed at the grass roots with appropriate awareness campaigns aimed at an understanding that the insights generated by such research is the basis for future disease treatment or even eradication.'

The active involvement of such scientists as part of administration of funding agencies is another aspect that may readjust the cultural thinking of such agencies towards developing an understanding of the importance and need for basic sciences research as they would bring in a different perspective based on their experiences.'

Translational medicine is another aspect that can be developed with involvement of both basic and applied scientists on the pattern of programs by National Institute of Health (NIH).

Thus acquiring fundamental knowledge of biological systems through basic sciences research would lead to healthier living by reducing disability and illness. Basic sciences at Khyber Medical University is also working on joint collaborative programs like nutrition and cancer genetics with research groups comprised of not only basic scientists but clinicians and epidemiologists as well.

\section{REFERENCES}

I. Hobin JA, Deschamps AM, Bockman R, Cohen S, Dechow P, Eng $C$, et al. Engaging basic scientists 
in translational research: identifying opportunities, overcoming obstacles. J Transl Med $2012 \mathrm{Apr}$ I3;10:72. DOI: 10.1186/14795876-10-72.

2. Schauz D. What is Basic Research? Insights from Historical Semantics. Minerva 20I4;52(3):273-328. DOI: |0.|007/s | |024-0|4-9255-0

3. Schor NF. Why our patients (and we) need basic science research. $\mathrm{Neurology} 2013 \mathrm{May}$ 28;80(22):2070-5. DOI: 10.1212/ WNL.0b0 I 3e3 I8294b48a.

4. Samuelsson B. Role of basic science in the development of new medicines: examples from the eicosanoid field. J Biol Chem 2012 Mar 23;287(I3): 10070-80. DOI: I0.1074/jbc.X| | 2.35|437.

5. Chan IS, Ginsburg GS. Personalized medicine: progress and promise. Annu Rev Genomics Hum Genet 2011 Sep 22;12(I):217-44. DOI: I0. I |46/annurev-genom-0824 I0101446.

6. Dao HD, Kota P, James JA, Stoner JA, Akins DR. Assessment of Translational and Interdisciplinary Clinical Research at an Oklahoma Health Sciences Center. J Okla State Med Assoc 20I5 Mar; I08(3):93-I0I.

7. Deckelbaum RJ, Ntambi JM, Wolgemuth DJ. Basic science research and education: a priority for training and capacity building in developing countries. Infect Dis Clin North Am 20 I I Sep;25(3):66976, x. DOI: I0.1016/j.idc.201 I.05.009.

8. Rochmyaningsih $\mathrm{D}$. The developing world needs basic research too. Nature 2016 Jun 1;534(7605):7. DOI: 10.1038/534007a.

9. Vink S, van Tartwijk J, Verloop N, Gosselink M, Driessen E, BolkJ. The articulation of integration of clinical and basic sciences in concept maps: differences between experienced and resident groups. Adv Health Sci Educ Theory Pract 2016 Aug;2I (3):643-57. DOI: I0.1007/s |0459-0I5-9657-2.
CONFLICT OF INTEREST

Authors declared no conflict of interest GRANT SUPPORT AND FINANCIAL DISCLOSURE NIL 